\title{
ESTILOS E GÉNEROS MUSICAIS NO ENSINO ARTÍSTICO ESPECIALIZADO DA MÚSICA EM PORTUGAL: PASSADO, PRESENTE E PERSPETIVAS FUTURAS
}

\author{
MUSICAL STYLES AND GENRES IN THE SPECIALIZED ARTISTIC TEACHING OF \\ MUSIC IN PORTUGAL: PAST, PRESENT AND FUTURE PERSPECTIVES
}

\author{
Sidónio Manuel da Costa Oliveira ${ }^{1}$ \\ António José Pacheco Ribeiro ${ }^{2}$
}

\begin{abstract}
RESUMO: O presente artigo explora as diferentes músicas e pedagogias subjacentes ao currículo das escolas públicas de Ensino Artístico Especializado da Música em Portugal. Neste sentido, pretende contribuir para o conhecimento da realidade musical do país, nomeadamente no que concerne às tipologias musicais, ou seja, aos géneros e estilos musicais praticados pelas escolas públicas de música, e, consequentemente, possibilitar a adoção de estratégias e medidas políticoculturais que consolidem os projetos educativos das escolas intervenientes, reforçando a sua autonomia pedagógica e as insira, efetivamente, nas suas comunidades locais/regionais, mas também na educação global de todos os indivíduos.
\end{abstract}

Palavras-chave: Ensino Público. Ensino Vocacional da Música. Ensino Artístico Especializado. Educação Musical.

ABSTRACT: This article explores the different musics and pedagogies underlying the curriculum of public schools of Specialized Artistic Teaching of Music in Portugal. In this sense, it intends to contribute to the knowledge of the musical reality of the country, namely in what concerns musical typologies, i.e., musical genres and styles practiced by public music schools, and, consequently, to

\footnotetext{
${ }^{1}$ Licenciatura em Música pela Escola Superior de Educação do Instituto Politécnico de Bragança, tendo sido o melhor aluno finalista da Licenciatura - Música no ano letivo de 2011/2012. Concluiu o Mestrado em Educação Musical do Ensino Básico e Secundário da Escola Superior de Educação do Instituto Politécnico de Bragança no ano letivo 2013/2014. Tem lecionado Educação Musical, Expressão Musical e Atividade Lúdica-Expressiva em Escolas Básicas. Atualmente, leciona Expressão Musical, Culturas Musicais em Contexto e Oficina de Animação Musical na Escola Superior de Educação do Instituto Politécnico de Bragança. Frequenta o Doutoramento em Estudos da Criança na Especialidade de Educação Artística - Educação Musical do Instituto de Educação da Universidade do Minho. Seus interesses de pesquisa são Educação Musical, Expressão Musical, pedagogias musicais no ensino básico e secundário e as políticas educacionais de ensino de música. E-mail:. sidonio.oliveira@ipb.pt.
}

2 Licenciado em Ensino de Música pela Universidade de Évora e Mestre em Estudos da Criança Especialização em Educação Musical pela Universidade do Minho. Realizou a parte letiva do Curso de Mestrado em Etnomusicologia na Universidade de Aveiro. Doutorou-se na Especialidade de Educação Musical, em Estudos da Criança, na Universidade do Minho. O seu interesse de pesquisa centra-se no ensino artístico especializado da música em Portugal, e na etnomusicologia e música tradicional, áreas em que tem desenvolvido diversos projetos de interação com a sociedade. Leciona no Conservatório do Vale do Sousa, Lousada, e no Instituto de Educação da Universidade do Minho. É membro integrado do Centro de Investigação em Estudos da Criança (CIEC). E-mail: antoniopacheco@ie.uminho.pt. 
enable the adoption of strategies and political-cultural measures that consolidate the educational projects of the intervening schools, reinforcing their pedagogical autonomy and inserting them, effectively, in their local/regional communities, but also in the global education of all individuals.

Keywords: Public Education. Vocational Teaching of Music. Specialized Artistic Teaching. Music Education.

\section{INTRODUÇÃO}

O ensino da música no Ensino Artístico Especializado em Portugal (Conservatórios Públicos), levanta muitas questões, questões essas que vão ao encontro das suas origens, mas que também nos fazem pensar sobre o futuro deste tipo de ensino. Será um preceito os conservatórios públicos centrar, de forma conservadora no Ensino Artístico Especializado de Música, as aprendizagens musicais no ensino clássico da cultura musical ocidental? Haverá uma segmentarização dos géneros musicais no ensino vocacional: o sobre apreço da música erudita (ou conhecida também como música clássica), e a subestimação da música popular (terno amplo que engloba todos os outros estilos e géneros musicais)? Que legislação e reformas estruturais do ensino da música em Portugal promoveram uma remodelação dos processos e ramos educacionais, os diferentes cursos e regimes de frequência dos alunos e o seu público alvo? Quais os fundamentos orientadores da organização e da gestão dos currículos do ensino básico? Qual é a autonomia pedagógica e organizativa das escolas públicas do Ensino Artístico Especializado de Música, face à necessidade de desenvolver competências musicais e sociais nos alunos, sendo mais abrangente nos estilos e géneros musicais que lecionam para que a música seja um ponto de interesse e motivação para os alunos, num reforço do ensino para todos e de uma escola inclusiva? Atualmente, há inúmeras teorias sobre o ensino e a aprendizagem da música; há nomes incontornáveis da pedagogia musical que hoje dão uma nova dimensão à educação musical; há escolas por todo o mundo que vão adaptando os seus currículos e programas às necessidades do século XXI.

\section{O currículo e a música erudita ocidental}

O dogma de centrar as aprendizagens do ensino vocacional da música no ensino clássico da cultura musical ocidental perfaz o ensino da música como convencional. A segmentarização dos géneros musicais no ensino vocacional, traduzidos como o sobre apreço da música erudita - também conhecida como música clássica, culta ou séria (CASTELO-BRANCO, 2010) - e a subestimação da música popular, entendida neste sentido como toda a música que não é erudita, que inclui o Blues, o Jazz, o Rock e as suas versões comerciais, a música Folclórica, entre muitos outros tipos musicais, mas também associada aos "[...] processos de produção massificada e de transformação da música 
numa mercadoria, produzida e comercializada pelas indústrias culturais, concretamente pela indústria da música" (CASTELO-BRANCO, 2oro, p. 876), é uma realidade no Ensino Artístico Especializado da Música em Portugal, que se manifesta desde a criação do Conservatório de Música de Lisboa, ligado à Casa Pia em (1835). Os métodos de ensino subjacentes ao ensino e aprendizagem da música, neste contexto, assentam em modelos herdados do século XIX e funcionam numa perspetiva tradicional, com características muito particulares de uma determinada sociedade, revelando pouca ou nenhuma ambição curricular (PACHECO, 2008).

Neste sentido, qual é o lugar e o papel da música popular e da música erudita nas Escolas Públicas de Música do Ensino Artístico Especializado? Ferreira, Vieira (2013, p. 87) descrevem que no ensino genérico, ensino especializado - vocacional e ensino profissional da música - “[...] existe uma sobrevalorização do conhecimento musical ligado à cultura erudita ocidental - embora no ensino genérico haja uma maior abertura para outros tipos de géneros e aprendizagens". Uma situação recorrente, mesmo depois das grandes reformas estruturais do ensino em Portugal, com a Lei $n .^{\circ}$ 5/73, de 25 de julho, (onde se definem os princípios fundamentais da educação, apostando num sistema educativo contemporâneo para garantir uma escola inclusiva), e da reforma do ensino artístico especializado, com o Decreto-Lei n. ${ }^{\circ}$ 310/83, de I de julho, que insere o ensino artístico nos moldes gerais de ensino em vigor através da reconversão dos Conservatórios de Música em Escolas Básicas e Secundárias, criando as respetivas Escolas Superiores de Música inseridas na estrutura de Ensino Superior Politécnico, remodelando os processos e ramos educacionais, os diferentes cursos e respetivos regimes de frequência dos alunos. Transformações importantes para o ensino da música, que ao longo das suas sucessivas remodelações e reestruturações, ainda assenta "[...] em ambiguidades e indefinições que ainda hoje caracterizam este subsistema de ensino" (PACHECO, 2008, p. 36), levantando questões quanto aos modelos pedagógicos e aos processos de ensino e aprendizagem neles envolvidos, atualmente.

Apesar da intensificação educativa no estudo das artes nas escolas públicas com a Portaria n. $691 / 2009$, de 25 de junho, que cria os Cursos Básicos de Dança, de Música e de Canto Gregoriano e aprova os respetivos planos de estudo; com a Portaria no 225/2012, de 30 de julho que cria o Curso Básico de Dança, o Curso Básico de Música e o Curso Básico de Canto Gregoriano dos 2.ำ e 3. Ciclos do Ensino Básico e aprova os respetivos planos de estudo; e a Portaria n. ${ }^{2}$ 243-B/2012, de 13 de agosto, que cria os cursos secundários artísticos especializados de Dança, de Música, de Canto e de Canto Gregoriano e aprova os respetivos planos de estudos ministrados em estabelecimentos de ensino público e particular e cooperativo; e, mais recentemente, a Portaria n. $223-\mathrm{A} / 2018$, de 3 de agosto, que procede à regulamentação das ofertas educativas do ensino básico, designadamente o ensino 
básico geral e os cursos artísticos especializados, definindo as regras e procedimentos da conceção e operacionalização do currículo dessas ofertas, bem como da avaliação e certificação das aprendizagens, tendo em vista o Perfil dos Alunos à Saída da Escolaridade Obrigatória, assim como

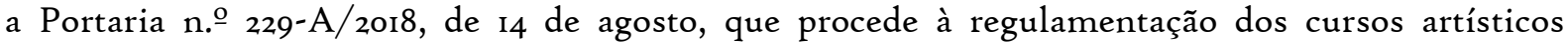
especializados de nível secundário, designadamente dos cursos de Dança, de Música, de Canto e de Canto Gregoriano, a situação do ensino da música em Portugal apresenta lacunas a nível curricular e pedagógico.

Há vários pontos manifestados nestes decretos e portarias que são ambíguos com a realidade atual. Por um lado, existem aspetos positivos que se destacam considerando "[...] a necessidade de todos os alunos poderem desenvolver as competências essenciais e estruturantes relativas a uma educação básica da escolaridade obrigatória" (PREÂMBULO DA PORTARIA n.ำ 691/2009, de 25 de junho), num reforço do ensino para todos e de uma escola inclusiva. Por outro lado, é necessário salvaguardar, de acordo com o Preâmbulo da Portaria n.ํㅡ 243-B/2012, de 13 de agosto:

A multiplicidade dos percursos formativos atualmente existentes no ensino artístico especializado nas áreas da Dança e da Música[que] implica, ainda, ponderação na entrada em vigor dos novos planos de estudos de modo a permitir uma adaptação progressiva às exigências das novas formações, tomando em consideração os percursos formativos dos alunos e as condições de funcionamento dos estabelecimentos de ensino.

Neste particular, as escolas artísticas, públicas e particulares e cooperativas, detêm o poder das decisões sobre o caminho mais adequado para cada novo desafio educativo do século XXI, tornando o cenário paradoxal. De acordo com Pacheco (2009, p. 106):

[...] numa análise crítica dos recentes processos e práticas de educação e formação, em especial desta primeira década do século XXI, colocamos no centro do debate a relação entre a globalização, conhecimento e currículo, de modo a salientar as mudanças ao nível da educação formal, não formal e informal para o estudo do currículo.

\section{O ensino não formal e informal da música}

Em conformidade com Vieira (2013), o ensino não formal e informal da música deve contribuir de forma positiva nas práticas pedagógicas formais, introduzindo outros géneros e estilos musicais que não os ditos eruditos, para promover a literacia musical, motivar a performance musical e desenvolver a autonomia do aluno para criar, compor e improvisar música. Com efeito, é necessário que os estabelecimentos do Ensino Artístico Especializado da Música, os professores e os alunos possam participar na construção de conhecimentos, procurando "[...] práticas de ensino musical 
alternativas aos modelos que ainda vão predominando na escola pública" (FERREIRA; VIEIRA, 2013, p. 87), sendo mais abrangentes nos géneros musicais que lecionam para que a música seja um ponto de interesse e motivação para os alunos.

Apesar de haver inúmeras instituições sociais que respondem ou permitam responder a diferentes necessidades humanas ou ocupações musicais das comunidades, e de se perspetivar uma abertura legislativa para diferentes géneros musicais, que não apenas o erudito nas escolas do Ensino Artístico Especializado de Música, as instituições do ensino vocacional de música de nível superior, deveriam ter um papel mais ativo na formação de professores e alunos e possibilitar opções de aprendizagens de géneros e estilos musicais que não estejam apenas centrados na música clássica ocidental. Ferreira, Vieira (2013, p. 89), salientam que:

[...] o conhecimento empírico, bem como os manuais escolares em vigor, revelam que não se verificou uma mudança muito substancial ao nível das estratégias utilizadas no processo específico de ensino e aprendizagem da música, tendo-se adaptado a aprendizagem desse repertório a procedimentos formais, e continuando assim a prevalecer um ensino expositivo [professor-transmissor de conhecimento e aluno-recetor], no qual se sobrevalorizam conhecimentos teóricos e notacionais da música, e não se promovem verdadeiras competências funcionais, nem se promove a autonomia do aluno.

Neste sentido, usando as palavras de Pacheco (2009, p.I12), questiono “[...] até que ponto a escola deixa de ser o veículo central do conhecimento em sociedades em que a desigualdade se faz a partir de critérios de infoexclusão", se atualmente há inúmeras teorias sobre o ensino e a aprendizagem da música. Há nomes incontornáveis da pedagogia musical que hoje dão uma nova dimensão à educação musical, permitindo que esta seja mais abrangente nos seus conteúdos e métodos de ensino. Neste contexto, temos o caso do processo de Apreciação Musical de Swanwick (1979, 2003, 2006) onde a audição desempenha um papel importante na apreciação musical do indivíduo que tem de estar mentalmente absorvido e envolvido pela experiência musical; a Teoria Espiral do Desenvolvimento Musical de Swanwick e Tillman (1986) que consiste no desenvolvimento musical e cognitivo das crianças em 4 etapas que se subdividem em dois modos evolutivos cada uma; a Audição Musical Activa de Wuytack e Palheiros (1995) desenvolvida para o ensino da audição a jovens não-músicos; a Audiação de Gordon (200o) sendo um processo de assimilação e compreensão do que se escuta pela mente atribuindo-lhe um significado pessoal pela imitação, pela memória e pelo reconhecimento do indivíduo em 8 tipos e 6 estádios de audiação; e o trabalho desenvolvido nos estudos sobre as aprendizagens informais e o ensino não formal de Green (2002, 2008) que consistem em adaptar e adotar aspetos das práticas informais de aprendizagem musical dos músicos populares nas 
aulas de música e educação musical da escola pública, dando aos alunos a escolha do repertório musical a estudar.

Todos estes autores assinalam a mudança sobre o ensino atual, e as suas " $[\ldots]$ diferentes transformações sociais, culturais e estéticas têm conduzido não só ao alargamento do conceito de música como também a cultura musical tem vindo a incorporar elementos emanados de outros contextos" (VASCONCELOS, 2007, p. 7), renovando a educação, visando não só o desenvolvimento de conteúdos rítmicos e tonais, mas também o desenvolvimento das competências intelectuais, pessoais e sociais dos alunos. Vieira (2013), salienta que quanto mais estreita for a conexão entre a escola e a sociedade, maior será a probabilidade de educarmos cidadãos autónomos, conscientes e pró-ativos para a comunidade.

É importante assinalar as várias e diferentes maneiras em que as pessoas realmente se relacionam e identificam com a música, e os professores necessitam de encontrar um método para que os alunos participem de uma forma mais ativa nas aulas (SWANWICK, 1979). A diversidade, multiculturalidade e interculturalidade da música remota no tempo, e colocam sobre os professores a obrigação de ajudar os alunos a desenvolverem, não apenas uma tolerância a um idioma musical restrito e elitista como o da música erudita ocidental, mas, a capacidade de se aproximarem ativamente a uma variedade de estilos e géneros, contextos e culturas musicais (SWANWICK, 1979). No entanto, as escolas de Ensino Artístico Especializado de Música continuam a implementar currículos e programas que se regem mediantes estereótipos da música clássica ocidental que, segundo Swanwick (2006), efetivam uma fronteira cultural para a educação; o mesmo autor, reforça o papel dos professores e dos alunos na tomada e partilha de decisões, na seleção, organização e ritmo das aprendizagens que se poderão realizar através de um método educacional aberto e informal. É inevitável e importante abordar uma filosofia educacional que seja abrangente nos dias que correm, porque " $[\ldots]$ o ensino musical ancorado nas perspectivas de séculos passados não responde aos pressupostos educativos e formativos associados às múltiplas linguagens musicais e propostas estéticas contemporâneas" (RIBEIRO, 2017, p. 5).

Neste contexto, e em conformidade com Ferreira, Vieira (2013), é necessário promover e potenciar pedagogias, estratégias e metodologias de ensino que incentivem as aprendizagens dos alunos. De facto, [...] "a escola não é, certamente, o único espaço de formação musical das crianças e dos jovens mas é sem dúvida, um dos mais importantes" (WUYTACK; PALHEIROS, 1995, p. 4950), e apesar de haver uma dissonância cultural entre a música que se aprende na escola e a música que os alunos escutam em casa (DOBROTA; ERCEGOVAC, 2017), é na sala de aula que "[...] a música pode tornar-se pouco significativa, e o interesse dos alunos provavelmente migra para outros 
campos" (SWANWICK, 2003, p. 42), porque “[...] a diferente procura não foi acompanhada pela necessária introdução de ofertas curriculares diversificadas capazes de responderem às novas expectativas e solicitações da população escolar" (RIBEIRO, 2017, p. 4), que hoje frequenta as escolas do Ensino Artístico Especializado de Música.

Nos dias que correm, efetivamente, "[...] os contextos de ensino são essencialmente produtores de identidades técnicas, já que os professores são mais avaliados e responsabilizados pelo lado dos resultados dos alunos do que pelo seu lado mais pessoal e de gestão de processos de aprendizagem" (PACHECO, 2009, p.i16). A evidência deste fator deve-se à realidade do favorecimento do ensino da música erudita nas escolas públicas e particulares e cooperativas do Ensino Artístico Especializado e os estudos realizados por Ferreira, Vieira (2013) e Brito, Vieira (2014) realçam este aspeto. Apesar de nas escolas genéricas já se estudar “[...] repertório musical de outras culturas que não a da Europa Ocidental (privilegiada sobretudo no ensino vocacional/especializado), bem como repertório tradicional português" (FERREIRA; VIEIRA, 2013, p. 89), “[...] o que é certo é que os programas oficiais de ensino especializado da música em Portugal assentam predominantemente no repertório designado por 'clássico' ou 'erudito' e no modelo pedagógico de ensino individual” (BRITO; VIEIRA, 2014, p. 109), como é o caso do estudo individual do instrumento.

\begin{abstract}
O modelo único de organização curricular e pedagógica, predominante no ensino especializado da música, que assenta na formação de instrumentistas solistas, ancorado numa perspectiva do século XIX e numa única tipologia musical, tem impedido que se dêem respostas adequadas à procura crescente da aprendizagem musical que correspondam à heterogeneidade dos territórios, dos alunos, dos públicos, dos profissionais e do desenvolvimento do mercado de emprego. [...] Por outro lado, é sabida a apetência dos adolescentes pelas linguagens da música Pop, do Jazz e, mais recentemente pelo fenómeno da World Music, que tem sido, nos melhores casos, um importante veículo de divulgação de culturas extra-europeias, ajudando a promover o respeito pela diferença e pelo "outro". A completa ausência destas e de outras tipologias nos actuais currículos e a subvalorização destes fenómenos culturais, pela maioria dos docentes, tem provavelmente causas muito semelhantes às que levam a uma não-aceitação, quase generalizada, da música do século XX. Esta constatação deve-nos levar a abordar sem preconceitos o problema da integração no currículo de outras tipologias musicais, entre as quais se encontram tipologias "mais próximas" dos alunos das nossas escolas FOLHADELA; VASCONCELOS; PALMA, 1998, p. 7-55).
\end{abstract}

Inúmeras questões se levantam quanto à finalidade educativa da música, e para dar respostas às exigências do século XXI será necessário transformar os currículos e programas institucionalizados há muito que, segundo Pacheco (2009, p. 108), devido a políticas educacionais, tendem "[...] para a homogeneidade e uniformização em detrimento da diversidade e identidade". Sem dúvida, é necessário dar importância ao público alvo e ao seu gosto musical, independentemente 
do seu futuro profissional (PACHECO, 2008), porque “[...] são raros os casos de alunos que chegam à escola com o objectivo particular de aprender 'música erudita' (ou 'clássica')" (BRITO; VIEIRA, 2014, p. 109).

É preciso desmistificar que o ensino da música do Ensino Artístico Especializado estará unicamente ligado à música erudita, e que a importância da articulação de aprendizagens mostra que o género e o estilo musical influenciam as aprendizagens dos alunos (GREEN, 2008). As instituições de ensino vocacional de música, necessitam de redefinir os currículos e programas escolares existentes, sendo imprescindível "[...] que haja algum espaço para a escolha, para a tomada de decisões, para a exploração pessoal" (SWANWICK, 2003, p. 67), quer dos professores, mas especialmente dos alunos. Assim, conseguimos aceitar "[...] como premissa que a educação responde a questões de conhecimento, perspectivado nas suas diferentes dimensões" (PACHECO, 2009, p. 124), porém, as Escolas Públicas e Particulares e Cooperativas do Ensino Artístico Especializado da Música “[...] são frequentadas por um número cada vez maior de crianças procurando diferentes saberes e conhecimentos, colmatando deficiências de formação que são particularmente sentidas pelas comunidades educativas" (RIBEIRO, 2017, p. 4).

\section{Música popular nos currículos}

Muitas investigações, por exemplo, nos países Escandinavos, nos Estados Unidos da América, no Canadá e no Reino Unido, reportam que os currículos dos Conservatórios, Academias e Instituições de Ensino Superior de Música já têm estabelecidos nos seus programas música popular (denominada também como popular music ou pop music), jazz, música tradicional (denominada também como folk music) e world music (HILL, 2009; LUBET, 2009; ANTTILA, 2010; WU, 2012; DYNDAHL; NIELSEN, 2014; PETERS, 2016).

Em Portugal, tal situação não é uma realidade, no entanto desenvolvem-se no âmbito das escolas do ensino particular e cooperativo determinados projetos informais que aproximam a música popular à música erudita. Neste particular, destaca-se o projeto pareSeres da terra levado a cabo no Conservatório do Vale do Sousa - Lousada, desde 2007, que desenvolve um programa de aproximação a outras tipologias musicais diferenciadas, nomeadamente à música popular/tradicional portuguesa, no sentido de responder às necessidades de renovação da escola de música (RIBEIRO, 2017). De acordo com Pacheco (2012, p. 5):

Este projecto inserido no âmbito da música popular/tradicional portuguesa [...] compreend[e]um conjunto de propostas que pretende $[\mathrm{m}]$ envolver a comunidade educativa em torno de uma ideia pedagógica/musical, criando espaços para 
reflexões, recriações e, essencialmente, sensibilizando para o património musical português, factor essencial da nossa identidade cultural.

O projeto pareSeres da terra tem-se afirmado e desenvolvido, desta forma, no Conservatório do Vale do Sousa, como consequência da problemática com que se depara o Ensino Artístico Especializado da Música em Portugal, desde a sua integração no sistema geral de ensino. Muito embora este projeto se desenvolva no âmbito da música portuguesa não erudita, a verdade é que esta tipologia musical é abordada através de um programa de currículo informal e não formal, e que as tipologias musicais não eruditas encontram forte resistência junto da população docente (RIBEIRO, 2017).

Neste contexto, é crucial dar importância às questões da multiculturalidade e pluralidade musical nos dias que correm (SWANWICK, 2003), e saber se há lugar para outras tipologias musicais no Ensino Artístico Especializado público em Portugal é uma pergunta pertinente face às condições de acompanhar os requisitos educacionais do século XXI, da escola inclusiva, da escola para todos, defendendo assim "[...] que o currículo, enquanto conteúdo de aprendizagem, estrutura e molda o sistema educativo, definindo quer a selecção e organização do conhecimento quer os itinerários de aprendizagem dos alunos em contextos de educação e formação formal, não formal e informal" (PACHECO, 2009, p. 126), para promover as suas identidades.

\section{Considerações finais}

O currículo e os programas vigentes do ensino da música no Ensino Artístico Especializado em Portugal, assentam numa única tipologia musical, ligada à música erudita ocidental, e num modelo pedagógico tradicional herdado do século XIX. Na década de 90 do século $\mathrm{XX}$, as transformações socioeconómicas ocorridas em Portugal fizeram com que o Ensino Artístico Especializado da Música sofresse um aumento significativo na sua procura alterando, significativamente, a população escolar afeta a este tipo de ensino. Neste sentido, as escolas de música são hoje frequentadas por crianças e jovens que procuram, no conceito de escola de música, outros saberes e conhecimentos que ultrapassam a especificidade de uma atividade profissional no âmbito da música. No entanto, a organização curricular e pedagógica deste tipo de ensino, apesar das diversas reestruturações do sistema após a sua inserção no sistema geral de ensino, não se alterou continuando ancorada numa perspetiva tradicional, impedindo respostas adequadas à diversidade da procura. 
Neste contexto, a ausência de outras tipologias musicais, ou seja, outros géneros e estilos musicais, nomeadamente a música popular, tão próxima da identidade dos alunos, no Ensino Artístico Especializado da Música nas escola públicas, tem contribuído para a falta de soluções no âmbito da oferta curricular existente. A não inclusão destas tipologias musicais no currículo destas escolas, por outro lado, não tem acompanhado a tendência que se manifesta nos restantes países da Europa e do resto do mundo, comprometendo, assim, o futuro deste tipo de ensino.

\section{Referências}

ANTTILA, Mikko. Problems with school music in Finland. British Journal of Music Education, Cambridge University Press, v. 27, n. 3, p. 241-253, set. 2010.

https://doi.org/I0.1017/So265051710000215

BRITO, Hugo Manuel; VIEIRA, Maria Helena. Sargaceiros de Apúlia e Orquestra de Cordas: Contributos para uma Etnopedagogia Musical. Revista Música Hodie, Goiânia, v. I4, n. 2, p. 99IIO, 2014 .

CASTELO-BRANCO, Salwa. (2010). Enciclopédia da Música em Portugal no Século XX. Vol. 3. Lisboa: Temas e Debates, 2010. 372 p.

DOBROTA, Snježana; ERCEGOVAC, Ina Reic. Music preferences with regard to music education, informal influences and familiarity of music amongst young people in Croatia. British Journal of Music Education, Cambridge University Press, v. 34, n. I, p. 41-55, mar. 2017.

DYNDAHL, Petter; NIELSEN, Siw Graabraek. Shifting authenticities in Scandinavian music education. Music Education Research, v. 16, n. I, p. 105-118, 2014. 10.1080/14613808.2013.847075

FERREIRA, Sónia; VIEIRA, Maria Helena. Práticas Formais e Informais no Ensino da Música: Questionando a Dicotomia. Revista Portuguesa de Educação Artística, v. 3, p. 85-96, 2013. FOLHADELA, Paula; VASCONCELOS, António Ângelo; PALMA, Eduardo. Ensino Especializado da Música Reflexões de Escolas e de Professores. Lisboa: ME - Departamento do Ensino Secundário, 1998. 112 p.

GORDON, Edwin. Teoria de Aprendizagem Musical: Competências, Conteúdos e Padrões. Lisboa: Fundação Calouste Gulbenkian, 2000. 513 p.

GREEN, Lucy. How Popular Musicians Learn: A Way Ahead for Music Education. London: Ashgate Publishing, 2002. $250 \mathrm{p}$.

GREEN, Lucy. Music, Informal Learning and the School: a New Classroom Pedagogy. . London: Ashgate Publishing, 2008. 226 p.

HILL, Juniper. The Influence of Conservatory Folk Music Programmes: The Sibelius Academy in Comparative Context. Ethnomusicology Forum, v. 18, n. 2, p. 207-241, nov. 2009.

DOI: 10.1080/17411910903141882 
LUBET, Alex. The inclusion of music/the music of inclusion. International Journal of Inclusive Education, v. 13, n. 7, p. 727-739, dez. 2009.

DOI: $10.1080 / 13603110903046010$

PACHECO, António. O Ensino da Música em Regime Articulado no Conservatório do Vale do Sousa: Função Vocacional ou Genérica? 2008. Isof. Dissertação (Mestrado em Estudos da Criança Educação Musical) -Instituto de Estudos da Criança, Universidade do Minho, Braga, 2008.

PACHECO, António. (Org.). um olhar cinco pareSeres. Lousada: Conservatório do Vale do Sousa, 2012. $57 \mathrm{p}$.

PACHECO, José Augusto. Processos e práticas de educação e formação. Para uma análise da realidade portuguesa em contextos de globalização. Revista Portuguesa de Educação, [S. l.], v. 22, n. I, p. 105-I43, 2018. DOI: 10.21814/rpe.13955.

Disponível em: https://revistas.rcaap.pt/rpe/article/view/r3955. Acesso em: I9 fev. 202I.

PETERS, Gretchen Do Students See Themselves in the Music Curriculum? A Project to Encourage Inclusion. Music Educators Journal, v. 102, n. 4, p. 22-29, jun. 2016.

https://doi.org/10.1177/oo27432116644330

PORTUGAL. Lei n. ${ }^{\mathbf{0}}$ /73, de 25 de julho - Aprova as bases a que deve obedecer a reforma do sistema educativo.

PORTUGAL. Decreto-Lei no 310/83, de I de julho - Insere o ensino artístico nos moldes gerais de ensino em vigor através da reconversão dos Conservatórios de Música em Escolas Básicas e Secundárias, criando as respetivas Escolas Superiores de Música inseridas na estrutura de Ensino Superior Politécnico.

PORTUGAL. Portaria no 691/2009, de 25 de junho - Cria os cursos básicos de dança, de música e de canto gregoriano e aprova os respetivos planos de estudo.

PORTUGAL. Portaria no 225/2012, de 30 de julho - Cria o Curso Básico de Dança, o Curso Básico

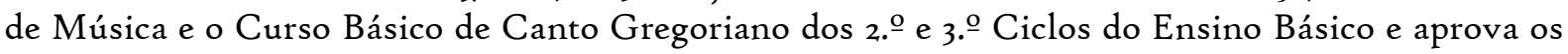
respetivos planos de estudo.

PORTUGAL. Portaria no 243-B/2012, de 13 de agosto - Cria os cursos secundários artísticos especializados de Dança, de Música, de Canto e de Canto Gregoriano e aprova os respetivos planos de estudos ministrados em estabelecimentos de ensino público, particular e cooperativo.

PORTUGAL. Portaria n. $223-\mathrm{A} / \mathbf{2 0 1 8}$, de 3 de agosto - Procede à regulamentação das ofertas educativas do ensino básico previstas no n. ${ }^{2}$ do artigo 7. ${ }^{\circ}$ do Decreto-Lei n. $55 / 2018$, de 6 de julho.

PORTUGAL. Portaria n. 229-A/2018, de 14 de agosto - Procede à regulamentação dos cursos artísticos especializados de Dança, de Música, de Canto e de Canto Gregoriano, a que se refere a

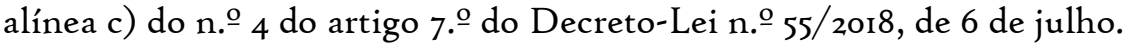

RIBEIRO, António José Pacheco. pareSeres da terra e a música popular portuguesa no Conservatório do Vale do Sousa. Revista Vórtex, Curitiba, v.5, n.3, p.I-20, 2017. 
SWANWICK, Keith . A Basis for Music Education. London: Routledge, 1979. 136 p.

SWANWICK, Keith. Ensinando Música Musicalmente. Tradução Alda Oliveira e Cristina Tourinho. São Paulo: Moderna, 2003. 128 p.

SWANWICK, Keith. Música, pensamiento y educación. 3. ${ }^{a}$ ed. Madrid: Ediciones Morata, 2006. $192 \mathrm{p}$.

SWANWICK, Keith; TILLMAN, June. The Sequence of Musical Development: A Study of Children's Composition. British Journal of Music Education, v. 3, n.3, p. 305-339, 1986.

doi:10.1017/So265051700000814

VASCONCELOS, António Ângelo. A música no ı. Ciclo de Ensino Básico: o estado, a sociedade, a escola e a criança. Revista de Educação Musical, n. 128-129, p. 5-15, set/dez. 2007.

VIEIRA, Maria Helena. Music literacy for enhance citizenship. What public schools can do for us. In: CAMPION, M. et al. (Orgs.). Changing the World: Social And Political Pedagogies in Civic Education. Braga: CIEC - Universidade do Minho, 2013. p. 85-ror.

WU, Sinae. Reflecting on the implications, problems and possibilities raised by the entrance of 'world musics' in music education. British Journal of Music Education, Cambridge University Press, v. 29, n. 3, p. 303-316, nov. 2012.

https://doi.org/ro.1017/So26505171200037X

WYUTACK, Jos; PALHEIROS, Graça Boal. Audição musical activa - livro do professor. Porto: Associação Wyutack de Pedagogia Musical, 1995. 108 p. 